\title{
O ser docente na Educação Profissional em Saúde: descortinando o universo representacional dos professores que atuam nessa formação
}

\author{
The being teacher in health professional education: decorating the \\ representational universe of the teachers who act in this training
}

Recebido: 17/05/2019 | Revisado: 20/06/2019 | Aceito: 20/01/2021 | Publicado: 19/04/2021

Anna Katyanne Arruda Silva e Souza ORCID: https://orcid.org/0000-0002-72579133

Escola de Saúde da Universidade Federal do Rio Grande do Norte

E-mail: annakaty@gmail.com

Erika dos Reis Gusmão Andrade ORCID: https://orcid.org/0000-0002-52968481

Centro de Educação da Universidade

Federal do Rio Grande do Norte (CE/UFRN)

E-mail: ergandrade@gmail.com

Como citar: SOUZA, A. K. A. S.; ANDRADE, E. R. G.; O ser docente na Educação Profissional em Saúde: descortinando o universo representacional dos professores que atuam nessa formação. Revista Brasileira da Educação Profissional e Tecnológica, [S.I.], v. 1, n. 20, p. e8636, abr. 2021. ISSN 2447-1801.

This work is licensed under a Creative Commons Attribution 4.0 Unported License.

\begin{abstract}
Resumo
Trata-se de um estudo descritivo-exploratório, com abordagem qualitativa, construído a partir de um recorte da dissertação "Representações Sociais de professores da Educação Profissional em Saúde sobre o ser professor", no qual se utilizou como aporte teórico-metodológico a Teoria das Representações Sociais (MOSCOVICI, 1961). Como instrumento de recolha dos dados foi utilizada a entrevista semiestruturada, analisada através do processo interpretativo das representações sociais preconizado por Arruda (2014), tendo como locus de pesquisa a Escola de Saúde da Universidade Federal do Rio Grande do Norte. Este artigo objetiva discutir as dimensões do ser docente na Educação Profissional em Saúde, a partir do entendimento do universo representacional sobre esse objeto de estudo partilhado por professores que atuam na formação em saúde na Rede Federal de Educação Profissional e Tecnológica (RFEPT).
\end{abstract}

Palavras-chave: Representações Sociais. Educação Profissional em Saúde. Docência.

\begin{abstract}
It is a descriptive-exploratory study with a qualitative approach, based on a report from the dissertation "Social Representations of Teachers of Professional Education in Health on the teacher", not qualified as a theoreticalmethodological teacher of Representational Theory Social (MOSCOVICl, 1961). As a data collection instrument was used for the semistructured interview, analyzing through the interpretative process of the social representations advocated by Arruda (2014), having as a research locus a School of Health of the Federal University of Rio Grande do Norte. This article aims to discuss the dimensions of the teaching staff in Health Education, starting from the understanding of the representational universe about the object of study shared by teachers who work in health education in the Professional and Technological Education Network.
\end{abstract}

Keywords: Social Representations. Professional Education in Health. Teaching. 


\section{INTRODUÇÃO}

São muitos os avanços e desafios experienciados pelos professores que atuam na Educação Profissional em Saúde - EPS - no Brasil, notadamente na Rede Federal de Educação Profissional e Tecnológica - RFEPT -. As exigências do mundo do trabalho, as inovações tecnológicas, o compromisso social desta formação com a consolidação e a melhoria do Sistema Único de Saúde e com a progressiva qualidade da assistência à saúde prestada à população, dentre outros fatores, tornam complexo o ensino que tem como finalidade a qualificação e capacitação de nível básico, técnico e tecnológico dos trabalhadores da área de saúde.

Nesse contexto, a Educação Profissional em Saúde, inserida no processo contraditório de formação humana e da força de trabalho para a produção em geral, tem sofrido algumas mudanças. As práticas pedagógicas dos professores da EPS, precisam se adequar diante das mudanças nas relações sociais, as complexas tecnologias e os nichos de trabalho qualificado, dessa forma refletir sobre o ser professor na EPS é fator imprescindível para a ressignificação dessas práticas, a melhoria do processo ensino-aprendizagem e o avanço da Educação Profissional em Saúde.

A partir dessa problemática, elencou-se como questão orientadora e norteadora da pesquisa: Que representações sociais os professores de Educação Profissional em Saúde possuem acerca do ser professor na EPS e que relações podem ser estabelecidas entre elas e o contexto em que estão inseridos?

A escolha por este objeto de estudo não se dá de forma isolada de um contexto importante para a discussão sobre a formação profissional no Brasil, mas se insere no contexto da expansão vivenciada pela Rede Federal de Educação Profissional, Científica e Tecnológica no país, no período de 2003 a 2016, aproximadamente; pelo comprometimento com a meta 11 do Plano Nacional de Educação, Lei 13.005/2014 para o decênio 2014-2024, que objetiva triplicar o número de matrículas em Educação Profissional técnica de nível médio em 10 anos; pelo dinamismo da formação profissional em saúde; e pela contínua necessidade de reformulação teórico-metodológica e organizacional/estrutural do ensino técnico e tecnológico em saúde, em virtude do crescimento e desenvolvimento deste ensino que impacta, direta e indiretamente, na profissionalização de trabalhadores em saúde e na melhoria da assistência à saúde da população.

O interesse nessa pesquisa também é especialmente atravessado pelo desenvolvimento das atividades profissionais de uma das pesquisadoras na unidade acadêmica especializada na formação profissional em saúde da Universidade Federal do Rio Grande do Norte - UFRN -, por sua formação acadêmica nas ciências da saúde e nas ciências humanas e pelo comprometimento assumido com o crescimento e desenvolvimento institucionais e a formação continuada dos profissionais envolvidos nesse processo educativo.

Esse contexto torna imprescindível refletir sobre como é ser professor responsável pela formação profissional em saúde, no que tange à compreensão das especificidades inerentes a este campo educacional, no qual problematizam-se frequentemente aspectos quantitativos como os relacionados à proporção aluno/professor em sala de aula, entre outros e também aspectos qualitativos, como os inerentes à qualificação e à capacidade de adaptação e empoderamento desses 
profissionais às contínuas transformações do mundo do trabalho, visando à profissionalização dos trabalhadores em saúde e a sua formação humana, cidadã e ética, a fim de elevar o nível de qualidade e humanização nos serviços de saúde.

Por compreendermos a constituição do ser professor como resultado da conjunção entre fatores individuais e coletivos, frutos do contexto e das interações humanas, este estudo encontra-se apoiado teórica e metodologicamente na Teoria das Representações Sociais proposta por Serge Moscovici (1961), uma vez que a representação social configura-se como um conjunto de conceitos, significações e interpretações construídos e partilhados entre os sujeitos, ou seja, é uma construção do sujeito como ser social. Sujeito que não é apenas produto de determinações sociais nem seu produtor independente, pois as representações são sempre construções contextualizadas, resultados das condições em que surgem e circulam e, principalmente, produções compartilhadas.

Partindo desse enunciado, o presente artigo tem por objetivo discutir as dimensões do ser docente na Educação Profissional em Saúde, a partir do entendimento do universo representacional sobre esse objeto de estudo partilhado por professores que atuam nesse contexto formativo na RFEPT. Trata-se, portanto, de um estudo descritivo-exploratório, com abordagem qualitativa, construído a partir de um recorte da dissertação "Representações Sociais de professores da Educação Profissional em Saúde sobre o ser professor", no qual se utilizou como aporte teóricometodológico a Teoria das Representações Sociais (MOSCOVICI, 1961). Como instrumento de recolha dos dados usamos a entrevista semiestruturada, analisada através do processo interpretativo das representações sociais preconizado por Arruda (2014).

\section{METODOLOGIA}

Trata-se de uma pesquisa exploratória descritiva, com abordagem qualitativa, norteada e estruturada através da realização de levantamento bibliográfico sobre estudos que abordam a temática em questão e de entrevistas semiestruturadas.

O desenvolvimento inicial da pesquisa ocorreu mediante a realização de um desenho das discussões sobre o "ser docente na Educação Profissional em Saúde e representação social" em 04 (quatro) bases de dados nomeadamente conhecidas: periódicos da Coordenação de Aperfeiçoamento de Pessoal de Nível Superior CAPES -, Biblioteca Digital Brasileira de Teses e Dissertações, Repositório Institucional do Programa de Pós-Graduação em Educação da Universidade Federal do Rio Grande do Norte e Repositório Institucional do Programa de Pós-graduação em Enfermagem da Universidade Federal do Rio Grande do Norte. Além destas três bases de dados, também foram apreciados os trabalhos apresentados na X Jornada Internacional sobre Representações Sociais e VIII Conferência Brasileira sobre Representações Sociais realizados no ano de 2017, através dos cadernos de programação do evento, uma vez que na época ainda não haviam sido disponibilizados os Anais dos referidos eventos.

A fase empírica da pesquisa teve como locus a Escola de Saúde (ESUFRN), unidade acadêmica especializada em saúde vinculada à Universidade Federal do Rio Grande do Norte, localizada à Avenida Senador Salgado Filho, Campus Universitário, 
s/n, bairro Lagoa Nova, CEP 59.072-970, cidade de Natal, Rio Grande do Norte, cujos cursos ofertados destinam-se a qualificar, atualizar e aperfeiçoar a comunidade e os trabalhadores da área da saúde, buscando mantê-los preparados para atuarem frente às mudanças constantes dos conhecimentos e saberes tecnológicos da área.

Elegemos como participantes do nosso estudo 11 (onze) professores da ESUFRN, como amostra de uma população constituída por 40 docentes, na faixa etária de 32 a 62 anos, residentes no estado do Rio Grande do Norte, sendo 10 do gênero feminino e 01 do gênero masculino, após saturação teórica durante a aplicação do instrumento de pesquisa. Todos participaram voluntariamente da pesquisa, após a concordância com o Termo de Consentimento Livre e Esclarecido e do Termo de Autorização para gravação de voz.

Os participantes foram selecionados pelo critério de inclusão na amostra definido como: docentes integrantes do quadro de professores efetivos da Escola de Saúde da UFRN, na cidade de Natal, estado do Rio Grande do Norte, em pleno exercício de suas atividades, e que atuem em diversos níveis de ensino da Educação Profissional em Saúde, para uma melhor compreensão das pretensões do estudo, uma vez que sua vivência e experiência no ensino ofertado pela Instituição favorecerá a compreensão dos objetivos do estudo.

A amostra foi selecionada por meio da comprovação de envolvimento dos docentes na Educação Profissional em Saúde através da consulta ao Sistema Integrado de Gestão Acadêmica - SIGAA - da UFRN, onde constam as disciplinas ministradas pelos mesmos. A atuação na Educação Profissional em Saúde também foi consultada através da ficha funcional dos docentes cuja consulta foi disponibilizada previamente pela Secretaria da Direção Geral da ESUFRN. A caracterização dos participantes do estudo é apresentada no Quadro 1.

Quadro 1: Caracterização dos participantes do estudo

\begin{tabular}{|c|c|c|c|c|c|c|c|}
\hline $\begin{array}{l}\text { Parti } \\
\text { cipa } \\
\text { ntes }\end{array}$ & Idade & Gênero & $\begin{array}{c}\text { Formação } \\
\text { inicial }\end{array}$ & Titulação & $\begin{array}{l}\text { Tempo de } \\
\text { trabalho } \\
\text { como } \\
\text { professor }\end{array}$ & $\begin{array}{c}\text { Tempo } \\
\text { de } \\
\text { trabalho } \\
\text { na EPS }\end{array}$ & $\begin{array}{c}\text { Tempo } \\
\text { de } \\
\text { trabalho } \\
\text { como } \\
\text { profess } \\
\text { or na } \\
\text { Instituiç } \\
\text { ão }\end{array}$ \\
\hline $\mathrm{R} 1$ & $\begin{array}{c}34 \\
\text { anos }\end{array}$ & Feminino & $\begin{array}{c}\text { Licenciatura/B } \\
\text { acharelado }\end{array}$ & Doutorado & 11 anos & 11 anos & 11 anos \\
\hline $\mathrm{R} 2$ & $\begin{array}{c}62 \\
\text { anos }\end{array}$ & Feminino & $\begin{array}{c}\text { Licenciatura/B } \\
\text { acharelado }\end{array}$ & Mestrado & 43 anos & 19 anos & 39 anos \\
\hline R3 & $\begin{array}{c}31 \\
\text { anos }\end{array}$ & Feminino & $\begin{array}{l}\text { Licenciatura/B } \\
\text { acharelado }\end{array}$ & Mestrado & 11 anos & 11 anos & 08 anos \\
\hline R4 & $\begin{array}{c}32 \\
\text { anos }\end{array}$ & Feminino & $\begin{array}{l}\text { Licenciatura/B } \\
\text { acharelado }\end{array}$ & Doutorado & 06 anos & 03 anos & 05 anos \\
\hline $\mathrm{R} 5$ & $\begin{array}{c}32 \\
\text { anos }\end{array}$ & Masculino & $\begin{array}{l}\text { Licenciatura/B } \\
\text { acharelado }\end{array}$ & Doutorado & 10 anos & 04 anos & 02 anos \\
\hline $\mathrm{R} 6$ & $\begin{array}{c}32 \\
\text { anos }\end{array}$ & Feminino & $\begin{array}{l}\text { Licenciatura/B } \\
\text { acharelado }\end{array}$ & Mestrado & 06 anos & 03 anos & 03 anos \\
\hline
\end{tabular}


Revista Brasileira da Educação Profissional e Tecnológica, v. 1, n. 20, e8636, 2021, p. 5 de 17 CC BY 4.0 | ISSN 2447-1801 | DOI: https://doi.org/10.15628/rbept.2021.8636

\begin{tabular}{|c|c|l|c|c|c|c|c|}
\hline R7 & $\begin{array}{c}53 \\
\text { anos }\end{array}$ & Feminino & Bacharelado & Mestrado & 11 anos & 10 anos & 10 anos \\
\hline R8 & $\begin{array}{c}44 \\
\text { anos }\end{array}$ & Feminino & $\begin{array}{c}\text { Licenciatura/B } \\
\text { acharelado }\end{array}$ & Doutorado & 20 anos & 20 anos & 18 anos \\
\hline R9 & $\begin{array}{c}39 \\
\text { anos }\end{array}$ & Feminino & Bacharelado & Doutorado & 10 anos & $\begin{array}{c}02 \text { anos e } \\
\text { meio }\end{array}$ & $\begin{array}{c}02 \text { anos } \\
\text { e meio }\end{array}$ \\
\hline R10 & $\begin{array}{c}51 \\
\text { anos }\end{array}$ & Feminino & $\begin{array}{c}\text { Licenciatura/B } \\
\text { acharelado }\end{array}$ & Doutorado & 16 anos & 10 anos & 10 anos \\
\hline R11 & $\begin{array}{c}58 \\
\text { anos }\end{array}$ & Feminino & $\begin{array}{c}\text { Licenciatura/B } \\
\text { acharelado }\end{array}$ & Mestrado & 36 anos & 36 anos & 36 anos \\
\hline
\end{tabular}

Fonte: Dados da pesquisa, 2017

A descrição e discussão dos dados foram realizadas com base no diálogo com a literatura sobre a temática produzida por expoentes do campo da educação, trabalho e saúde, e do aporte teórico-metodológico da Teoria das Representações Sociais proposta por Serge Moscovici. Neste caminho téorico-metodológico, realizamos a análise das entrevistas semiestruturadas, por meio da construção de uma categorização "espontânea" que emergiu das falas dos professores no campo empírico através do processo interpretativo das representações sociais preconizado por Arruda (2014).

Tendo como base a análise dos dados obtidos nas entrevistas e a Teoria das representações sociais, a interpretação dos dados foi consolidada à luz do diálogo com os pressupostos teóricos acerca da Educação Profissional/ Educação e Trabalho, pautados nos teóricos Machado (2008); Ramos (2007, 2011); Kuenzer (2008); Ciavatta e Ramos (2012); Pereira $(2007,2008)$ Pereira e Ramos (2008, 2013); nos estudos sobre Práticas Pedagógicas/Formação docente, através das ideias de Tardif (2014); Freire (2014; 2011); Pimenta (2012); Perrenoud (2000; 2002); Nóvoa (1995; 2008); nos trabalhos sobre Representações sociais ancorados nos estudos de Moscovici (2012, 2015); Jodelet (2001); Arruda (2014), entre outros, e nas fontes documentais que regulamentam a Educação Profissional e Tecnológica, especificamente em Saúde como a Lei no 9.394/1996, Lei de Diretrizes e Bases da educação Nacional (LDB); Lei no 11.741/2008 que altera a LDB objetivando redimensionar, institucionalizar e integrar as ações da Educação Profissional Técnica de Nível Médio, da Educação de Jovens e Adultos e da Educação Profissional e Tecnológica; o Decreto no 5154/2004, que regulamenta os Artigos 36 e 39 a 41 da LDB, no que se refere à Educação Profissional e Tecnológica e apresenta três formas de articulação entre a Educação Profissional Técnica de Nível Médio e o Ensino médio: integrada, concomitante e subsequente; e a Resolução CNE/CEB no 6/2012, com fundamento no Parecer CNE/CEB no 11/2012, que define Diretrizes Curriculares Nacionais para a Educação Profissional Técnica de Nível Médio.

O estudo foi desenvolvido respeitando-se as diretrizes e normas regulamentadoras de pesquisas envolvendo seres humanos, em conformidade com a Resolução do Conselho Nacional de Saúde $N^{\circ} 466$, de 12 de dezembro de 2012. O projeto foi enviado ao Comitê de Ética localizado na UFRN e aprovado tendo como identificador do projeto, o Certificado de Apresentação para Apreciação Ética (CAAE) sob o $\mathrm{N}^{\circ}$ 61994716.1.0000.5537, com parecer favorável sob o № 1.850.672. 


\section{RESULTADO E DISCUSSÕES}

Neste tópico são apresentadas a descrição e discussão dos resultados da pesquisa através da exposição das dimensões representativas do ser professor da EPS no contexto da UFRN, que emergiram do processo de análise dos dados coletados durante a fase empírica, a partir do diálogo entre os achados de pesquisa e estudos que tratam da temática e expondo o que acreditamos ser indícios de uma representação social a respeito do ser professor na Educação Profissional em Saúde.

\subsection{A COMPLEXIDADE DO SER DOCENTE NA EDUCAÇÃO PROFISSIONAL EM SAÚDE}

A complexidade inerente ao ser docente na EPS evidencia-se nas falas dos participantes do estudo através de conteúdos representacionais relacionados às motivações para o ensino, à formação acadêmico-profissional, à concepção, ao perfil docente e aos fatores/estratégias que interferem na ação docente. Através destes conteúdos, pelo menos (04) quatro dimensões do ser docente emergem da análise das entrevistas (Quadro 1): dimensão objetiva e/ou de finalidade, dimensão afetiva e/ou do esforço, dimensão da realização pessoal e/ou profissional e dimensão do processo de ensino-aprendizagem.

Quadro 2: Dimensões representativas do ser professor na EPS

\begin{tabular}{|c|c|c|c|}
\hline $\begin{array}{c}\text { Dimensão } \\
\text { objetiva e/ou de } \\
\text { finalidade }\end{array}$ & $\begin{array}{c}\text { Dimensão afetiva e } \\
\text { do esforço }\end{array}$ & $\begin{array}{l}\text { Dimensão da } \\
\text { realização } \\
\text { pessoal e/ou } \\
\text { profissional }\end{array}$ & $\begin{array}{l}\text { Dimensão do } \\
\text { processo de ensino- } \\
\text { aprendizagem }\end{array}$ \\
\hline $\begin{array}{l}\text { Propiciar às } \\
\text { pessoas o } \\
\text { exercício digno de } \\
\text { uma profissão }\end{array}$ & $\begin{array}{l}\text { Otimização de } \\
\text { recursos }\end{array}$ & Realização & $\begin{array}{l}\text { Tripé saúde-trabalho- } \\
\text { educação }\end{array}$ \\
\hline Ser um motivador & Sensibilidade & Alegria & $\begin{array}{c}\text { Relação entre } \\
\text { qualidade da docência } \\
\text { e qualidade da } \\
\text { atenção à saúde }\end{array}$ \\
\hline $\begin{array}{c}\text { Conhecer a história } \\
\text { da EPS }\end{array}$ & Transição & Gostar do que faz & $\begin{array}{c}\text { Ensino por } \\
\text { competências }\end{array}$ \\
\hline $\begin{array}{l}\text { Facilitar o } \\
\text { aprendizado }\end{array}$ & Preocupação/angústia & Satisfação & Diálogo \\
\hline Formar o cidadão & Excesso de atividade & Comprometimento & $\begin{array}{l}\text { Aspectos psicossociais } \\
\text { da aprendizagem }\end{array}$ \\
\hline $\begin{array}{l}\text { Preparar o aluno } \\
\text { para ser um } \\
\text { diferencial }\end{array}$ & Falta de tempo & $\begin{array}{l}\text { Crescimento } \\
\text { profissional }\end{array}$ & Experiência e equipe \\
\hline $\begin{array}{l}\text { Preparar mão-de- } \\
\text { obra qualificada }\end{array}$ & $\begin{array}{l}\text { Instrumentalização do } \\
\text { docente }\end{array}$ & Oportunidade & $\begin{array}{l}\text { Diversidade de perfil } \\
\text { discente }\end{array}$ \\
\hline
\end{tabular}




\begin{tabular}{|c|c|c|c|}
\hline $\begin{array}{l}\text { Conciliar teoria- } \\
\text { prática }\end{array}$ & Compromisso social & Naturalidade & Formação humana \\
\hline $\begin{array}{l}\text { Adequar o } \\
\text { processo ensino- } \\
\text { aprendizagem }\end{array}$ & Profissionalização & Identificação & $\begin{array}{l}\text { Diferente de outros } \\
\text { níveis }\end{array}$ \\
\hline $\begin{array}{l}\text { Colaborar com o } \\
\text { processo de } \\
\text { aprendizado }\end{array}$ & $\begin{array}{l}\text { Responsabilidade/ } \\
\text { ajuda }\end{array}$ & Exemplo & $\begin{array}{l}\text { Conhecimento do perfil } \\
\text { profissional do egresso }\end{array}$ \\
\hline $\begin{array}{l}\text { Buscar conhecer o } \\
\text { perfil do aluno }\end{array}$ & $\begin{array}{c}\text { Gratificação pessoal e } \\
\text { para o outro }\end{array}$ & Paixão & $\begin{array}{l}\text { Conhecimento } \\
\text { específico da área }\end{array}$ \\
\hline $\begin{array}{c}\text { Conhecer a } \\
\text { importância do } \\
\text { mundo do trabalho }\end{array}$ & Capacitação & Gratificação & $\begin{array}{l}\text { Conhecimento } \\
\text { didático-pedagógico }\end{array}$ \\
\hline Facilitador & $\begin{array}{l}\text { Falta de medo para } \\
\text { ousar/ não se } \\
\text { acomodar }\end{array}$ & Meta a alcançar & Formação integral \\
\hline $\begin{array}{c}\text { Viabilizar a } \\
\text { descoberta de } \\
\text { novas } \\
\text { possibilidades para } \\
\text { o aluno }\end{array}$ & $\begin{array}{l}\text { Aprendizagem com os } \\
\text { pares e educandos }\end{array}$ & Sonho & $\begin{array}{l}\text { Estratégias } \\
\text { metodológicas }\end{array}$ \\
\hline Avaliação & $\begin{array}{l}\text { Autoavaliação e } \\
\text { reflexão }\end{array}$ & $\begin{array}{l}\text { Quebra de } \\
\text { paradigmas }\end{array}$ & $\begin{array}{c}\text { Estímulo à } \\
\text { participação ativa do } \\
\text { educando }\end{array}$ \\
\hline
\end{tabular}

Fonte: Elaborado pela autora, com base nos dados do estudo, 2017.

No que tange à Dimensão objetiva e/ou de finalidade, destacaram-se principalmente nas falas dos participantes a preparação de mão-de-obra qualificada, o exercício digno de uma profissão, a conciliação entre teoria-prática e a formação do cidadão.

Na Dimensão afetiva e do esforço emergiram principalmente o desafio inerente à atividade, a responsabilidade, a gratificação pessoal e para o outro e a aprendizagem com os pares e os educandos.

Por sua vez, na Dimensão da realização pessoal e/ou profissional destacaram-se menções à realização, comprometimento, identificação e crescimento profissional.

Na Dimensão do processo de ensino-aprendizagem evidenciaram-se o tripé saúde-trabalho-educação, diálogo, conhecimento específico-conhecimento didático-pedagógico e formação humana.

Desse modo, elencamos como conteúdos representacionais para a construção do ser professor as relações entre trabalho, saúde e educação, entre educador, educando e compromisso social, entre conhecimentos específicos, experiência profissional e conhecimentos didático-pedagógicos, entre educador, educando e partilha, e entre autoavaliação e aprendizagem com os pares e os educandos, além de sobrecarga profissional, conciliação teoria-prática, dicotomia entre profissional da área de saúde e professor, afinidade e identificação.

Esses conteúdos emergem da análise dos aspectos pessoais, formativos e profissionalizantes identificados através da relação entre as experiências e vivências 
pessoais, acadêmicas e profissionais e o caminho percorrido para a constituição do ser professor na Educação Profissional em Saúde.

Entre essas experiências e vivências se destacam o tornar-se professor sendo professor, no cotidiano do processo de ensino-aprendizagem, a busca por distanciamento das experiências não exitosas como discente para a construção da identidade enquanto professor da EPS, a adaptação para a docência através do que os participantes apontam como "transferência do ser enfermeiro para o ser professor", a identificação de lacunas na formação inicial relacionada aos conhecimentos didático-pedagógicos que dificultaram a sua inserção na docência na EPS, sendo um fator estressor para esses envolvidos.

O conjunto de experiências e vivências no entremear da vida pessoal e profissional dos professores estão relacionados no nível micro e macro ao modo como objetivam o ser professor na Educação Profissional em Saúde como um desafio. No nível micro relaciona-se à necessidade de formação específica para ser professor no Ensino Básico, Técnico e Tecnológico - EBTT ${ }^{1}$-, que integra o ser e o fazer docente, no campo didático-pedagógico, além de atualizações requeridas pelo setor saúde para assegurar ao aluno uma formação qualificada e conectada às novas demandas do tripé saúde-trabalho-educação. No nível macro, relaciona-se ao compromisso social da EPS, à preocupação da qualidade da docência frente à qualidade da atenção à saúde prestada pelos egressos dos cursos e ao valor atribuído à educação para o trabalho.

A discussão sobre as facetas dessa representação social nos níveis micro e macro encontram fundamento na conexão entre o pensamento social e a vida cotidiana, uma vez que como pondera Jovchelovitch (2014), as relações entre os processos macro e micro, no caso desse estudo, respectivamente, compromisso social da Educação Profissional e formação específica para a docência na EBTT, não se fazem sem a ação cotidiana do sujeito psicossocial (docente consigo mesmo, docente com seus pares, docentes com discentes), do significado que eles dão à experiência vivida (a responsabilidade assumida individualmente e no grupo pela formação integral do futuro trabalhador a quem competirá cuidar do outro) e pela conexão que estabelecem com os processos sociais de que fazem parte (o compromisso com a formação profissionalizante de cidadãos que pretendem ingressar no mundo do trabalho ou galgar novos caminhos já estando nele inserido).

Esse conjunto de experiências e vivências é reconhecido pelos professores como fator determinante para a organização de suas condutas e comportamentos e para a relação que estabelecem com os educandos e os pares. Essa relação define o ser docente na EPS como sujeito ativo, reconhecedor de sua incompletude e inconcretude, em constante aprendizado e adequação às demandas do mundo do trabalho, da saúde e da educação, voltado à construção de uma relação afetiva e de troca com os educandos. Tal aprendizado ocorre em prol do estabelecimento do melhor contexto e estruturas, para o desenvolvimento por estes últimos das competências e habilidades esperadas aos egressos dos cursos de nível básico, técnico e tecnológico da área de saúde.

\footnotetext{
${ }^{1}$ De acordo com a Lei $\mathrm{N}^{\circ}$ 12.772, de 28 de dezembro de 2012, a carreira de Magistério do Ensino Básico, Técnico e Tecnológico destina-se a profissionais habilitados em atividades acadêmicas próprias do pessoal docente no âmbito da educação básica e da educação profissional e tecnológica, conforme disposto na Lei no 9.394, de 20 de dezembro de 1996, e na Lei oㅜ 11.892, de 29 de dezembro de 2008.
} 
Um aspecto bastante relevante que se sobressaiu nos achados constituintes desta pesquisa foi a importância que os professores atribuem à história de vida, ao planejamento pessoal e profissional e às experiências acadêmicas, profissionais e pessoais, inclusive no contexto familiar, e suas implicações na construção do ser professor. Dentre essas implicações está o posicionamento sobre que tipo de ensino os professores pretendem desenvolver (comprometido com a participação ativa do educando e os objetivos formativos da EPS, com a autoavaliação e com a mentalidade aberta às novas demandas, em busca da formação integral dos estudantes) e de quais práticas educativas esperam se distanciar (tradicionais e engessadas, que limitam educador-educando e o ensino-aprendizagem). Além disso, destacam também o reconhecimento do inacabamento e da ausência de formação específica para atuar como docente na EPS, o que lhes leva à busca por formação continuada em serviço, entre outras.

A apropriação dos elementos basilares correspondentes à concepção de mundo do trabalho, da educação e da saúde, papéis do docente, do discente, da instituição e da Educação Profissional em Saúde, acerca da constituição pessoal, formativa e profissional destes sujeitos foram essenciais para o entendimento dos conteúdos representacionais evocados na discussão sobre as dimensões do ser professor na EPS como aspectos inerentes ao processo ensino-aprendizagem na prática cotidiana.

Não é possível, portanto, como aponta a Teoria das Representações Sociais, estabelecermos um recorte entre o universo exterior (o contexto da Educação Profissional em saúde no Brasil e a relação trabalho-saúde-educação) e o do indivíduo (grupo), esse último constituído pela falta de formação específica de professor para atuar na EPS. A inexistência desse recorte do qual trata Moscovici (2012) é claramente explicitada nos conteúdos representacionais evocados para a construção do ser professor que abrangem desde as relações entre trabalho, saúde e educação imersos no contexto exterior, àquelas que envolvem os participantes do processo de ensino-aprendizagem, no âmbito do indivíduo e do grupo explicitadas na Figura 1. 
Figura 1: Conteúdos representacionais relacionados às motivações e à formação dos professores que atuam na EPS

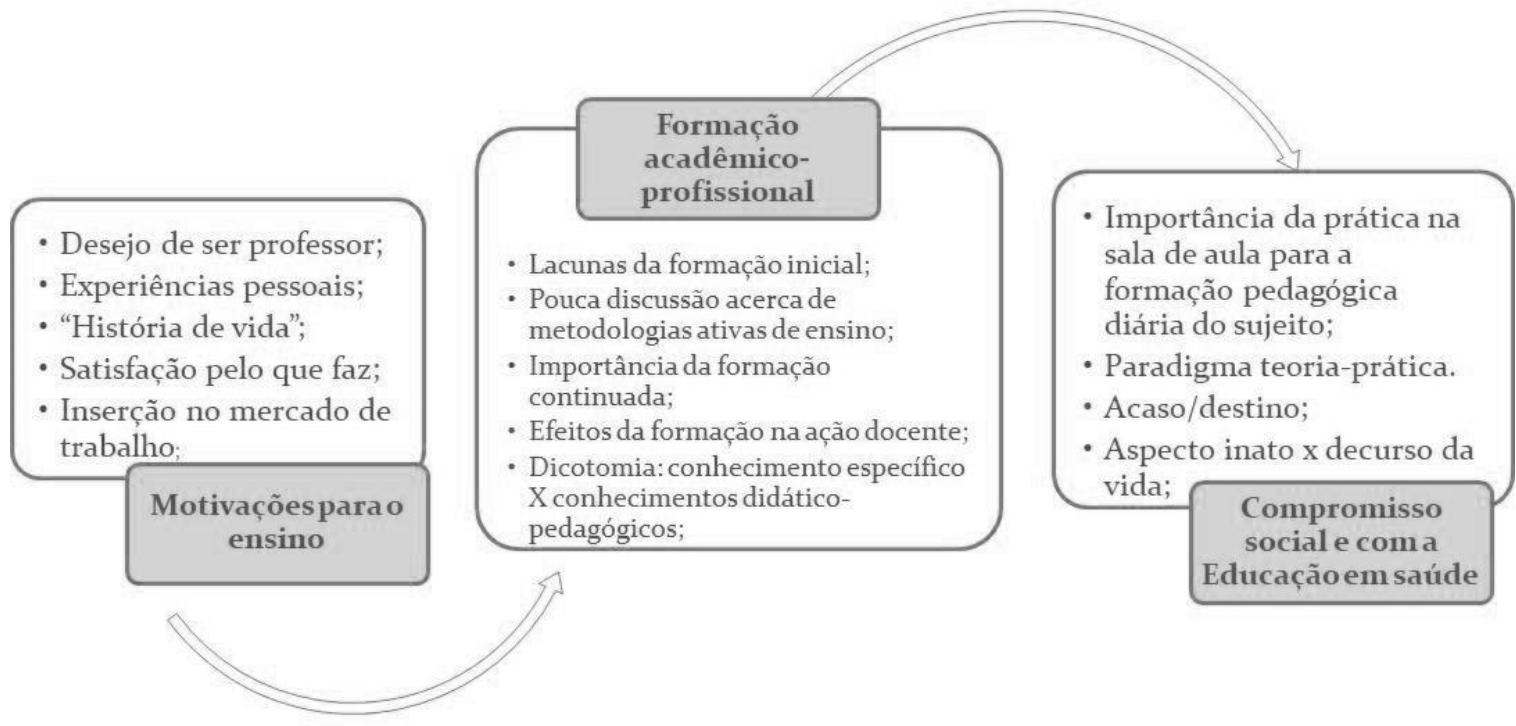

Fonte: Dados do estudo. Elaborado pela autora, 2017.

O entendimento do ser e fazer docentes na formação profissional em saúde através da análise das quatro dimensões explicitadas anteriormente permite desvelar a diversidade e complexidade de saberes que balizam a ação docente, dentre eles 0 saber da experiência, o saber curricular essencial à organização da atuação docente, o saber do conteúdo específico dos profissionais que atuam na atenção à saúde e o saber didático-pedagógico. Desse modo, munido dos conhecimentos técnicos e da expertise na área de saúde, espera-se que o professor possa utilizar as melhores estratégias e recursos que favoreçam o desenvolvimento das habilidades e competências pelo educando e conhecer as nuances de ordem psicossocial e cultural que nele interferem.

Como conceitos fundantes dessa ação docente emergiram alguns elementos da representação: a relação teoria-prática; a necessidade de preparar mão-de-obra qualificada para a assistência à saúde da população; a autoformação, autoavaliação e autorreflexão docentes sobre o seu fazer; e a relação professor-aluno. A importância da Instituição e da gestão para a constituição do ser docente, considerando que estes professores se tornam professores na prática de sala de aula, na construção cotidiana do saber dialógico com os educandos e demais sujeitos do processo educacional, também aparece em destaque nas falas dos participantes, uma vez que são oriundos de uma formação inicial extremamente específica e, por muitas vezes, fragmentada.

Além disso, foram também explicitadas pelos docentes questões relacionadas à carência de uma legislação que considere de forma plena as especificidades e complexidade deste modelo formativo e aos pré-conceitos e preconceitos sociais diante desta formação, resquícios de suas origens, e exemplificados na ideia errônea de uma formação menor, voltada para atender ao mercado de trabalho e com nítida distinção entre aqueles que possuem o saber e aqueles que executam as tarefas manuais. 
O tornar-se docente na Educação Profissional em Saúde no exercício da ação educativa cotidiana salientado nas falas dos participantes explicita as lacunas da formação inicial enquanto egressos de cursos da área de saúde e expressa a representação sobre ser docente como um desafio, que se revela na prática pedagógica como a materialização e naturalização do objeto ser docente na EPS.

Os resultados obtidos evidenciaram que o universo representacional destes professores acerca do ser professor é constituído por elementos relacionados às dimensões pessoais, formativas, profissionalizantes, do cotidiano docente e aos fatores específicos que interferem na EPS e que a construção real do ser professor está representada por sua experiência de estar professor, partilhando da representação social sobre ser professor enquanto desafio e produto das interações e dos fenômenos de comunicação no interior deste grupo social.

A construção da rede de sentidos advinda da análise das dimensões do ser professor aponta, por meio dos conteúdos representacionais evocados e explicitados anteriormente, a ideia de que o ser professor na Educação Profissional em Saúde envolve uma ancoragem em aspectos afetivo-emocionais (realização pessoal e profissional, compromisso com o outro e com o trabalho a que se propõe realizar, identificação e pertença com o mundo no qual estão inseridos) e em aspectos técnicocientíficos (conhecimento dos conteúdos específicos e didático-pedagógicos, experiência como trabalhador da área de saúde e objetivo formativo da EPS).

Estes aspectos asseguram a construção do ser professor, estando professor, ou seja, as representações do ser professor remetem inicialmente a uma formação inicial lacunar em relação à preparação para a docência, com forte apelo à formação específica para a atuação profissional na área de saúde e a um comprometimento com a formação continuada, especificamente com enfoque nos conteúdos pedagógicos voltados para o ensino. Envolve também a melhor compreensão das especificidades do que é ensinar dentro do contexto da Educação Profissional em Saúde e o compromisso social por eles assumido com a formação de profissionais responsáveis pelo cuidado em saúde, conforme apresentado na Figura 2. 
Figura 2: Conteúdos representacionais sobre o ser professor na EPS

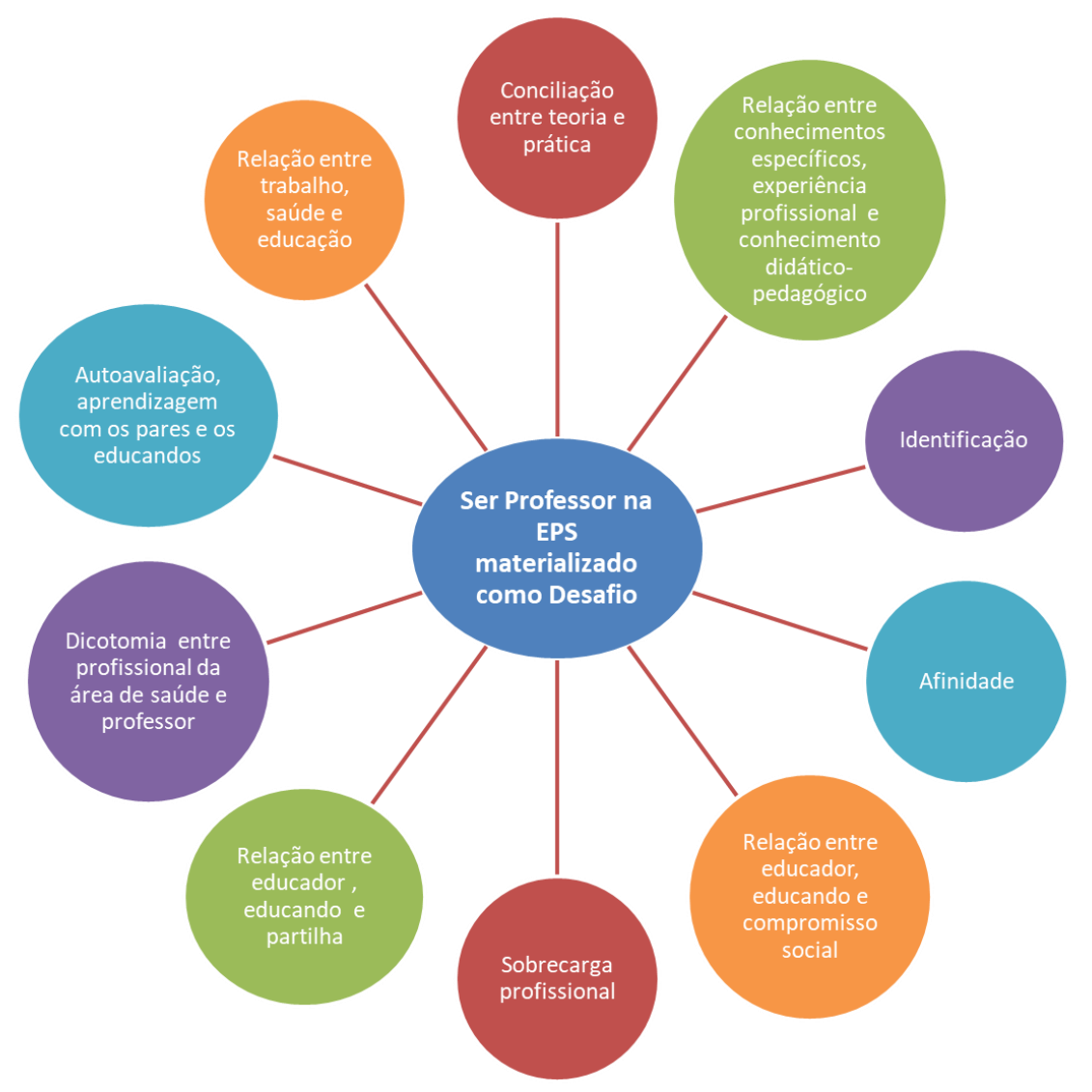

Fonte: Dados do estudo. Elaborado pela autora, 2018.

Essa rede de sentidos que para os professores dão significado e constituem o ser docente nessa formação nos faz recorrer à multifuncionalidade das representações sociais, ou seja, a organização significante do real que compreende a atribuição de sentido aos objetos e acontecimentos sociais; a comunicação, através de um sistema de categorização e de interpretação comuns, uma linguagem partilhada e a orientação das atividades avaliativas e explicativas, respeitando-se os consensos e dissensos dos grupos e entre-grupos; a orientação dos comportamentos, relacionada à modelagem e constituição de seus elementos; e, finalmente, a diferenciação social, relacionada a essa modelagem pelas relações intergrupais e ao papel de servir e justificar os comportamentos e avaliações (VALA, 1993).

A interseção entre os conteúdos que interferem na ação docente, nos leva a fazer menção à função das representações sociais de elaboração de comportamentos e comunicação entre indivíduos no quadro da vida cotidiana (MOSCOVICl, 2012), uma vez que entendendo o significado destes temas para este grupo podemos compreender esta modalidade específica de conhecimento, que advém do senso comum e é construída através dos processos de ancoragem e a objetivação.

O que observamos nesse caso é a função de popularização da "ciência" pedagógica pelos professores da escola e o poder convencional e prescritivo das representações sociais sobre a realidade que constituem o pensamento em um verdadeiro ambiente onde se desenvolve a vida cotidiana (MOSCOVICl, 2012). 
Sá (2015, p. 198) clarifica esses dois processos do seguinte modo: a objetivação está relacionada à função de "duplicar um sentido por uma figura, dar materialidade a um objeto abstrato", "naturalizá-lo", enquanto que a ancoragem consiste na função de "duplicar uma figura por um sentido, fornecer um contexto inteligível ao objeto, interpretá-lo".

Ainda sobre esses dois conceitos, Jodelet (2001) remete a ancoragem à integração cognitiva do objeto representado, independente de qual seja esse, a um sistema de pensamento social preexistente e nas transformações implicadas.

Desse modo, a classificação e a denominação durante o processo de ancoragem advém da comparação deste objeto representado com algo que já nos é familiar, na tentativa de tornar familiar aquilo que ainda não é familiar. Por sua vez, a objetivação envolve a descoberta da "qualidade icônica de uma ideia ou um ser imprecisos". Este último processo está relacionado com a atribuição de uma imagem a um conceito, é o processo através do qual um determinado grupo social atribui uma forma ao que está sendo representado (MOSCOVICl, 2012).

Jodelet (2001, p. 368) descreve que esse segundo processo constituinte das representações sociais se dá através

da 1) seleção e descontextualização de elementos da teoria, em função de critérios culturais, normativos; 2) formação de um núcleo figurativo, a partir dos elementos selecionados, como uma estrutura imaginante que reproduz a estrutura conceitual; 3) naturalização dos elementos do núcleo figurativo, pelo qual, finalmente, as figuras, elementos do pensamento, tornam-se elementos da realidade, referentes para o conceito.

O produto final desses dois processos, que não ocorrem de forma isolada e não podem ser compreendidos separadamente, visto que envolve um grande processo de engendramento recíproco entre conceito e percepção (SÁ, 2015), consiste no que entendemos como representações sociais, ou seja, um tipo de conhecimento do cotidiano, formado pela mistura de todos os tipos de conhecimentos que os grupos sociais tem acesso, quais sejam a ciência, o mito, a filosofia, a religião e o próprio senso comum.

Por meio desse sistema de classificação, denominação e atribuição de uma imagem, os professores da EPS desse estudo podem se apropriar do objeto "ser professor", imaginá-lo, elaborá-lo e associá-lo a algo que lhes seja conhecido, familiar e, em seguida, representá-lo, objetivando-o em sua prática cotidiana, em suas vivências, em suas relações, na comunicação e na interação com o outro.

Como discorre Sá (2015, p. 296), "no campo das representações sociais, alude-se genericamente ao papel das práticas como suportes das representações ou responsáveis por sua transformação", pois as representações sociais resultam de uma interação social concreta.

Dessa forma, podem ser encontrados vestígios de uma representação social sobre o ser professor atravessados fortemente por uma busca de identificação do grupo, reconhecimento social e superação de paradigmas histórico, culturais e sociais que delegavam a Educação Profissional a um ensino de segunda categoria. Com base 
no exposto, constatamos evidências de uma representação social de ser professor na Educação Profissional em Saúde voltada para o compromisso social dessa formação com a capacitação e a qualificação de trabalhadores capazes de atuar de forma crítica e reflexiva em diversos níveis de atenção e serviços de saúde, com competência e habilidade técnico-científica, além de formação humana e integral.

Reforçamos, portanto, que no caminho percorrido pelos professores para apropriação do objeto e a consequente atribuição de sentido e significação (de pertença, de familiaridade, de identidade em relação ao objeto ser professor), eles se apoiam em um conjunto de saberes que são valorosos para eles enquanto integrantes de um mesmo grupo, quer sejam saberes teóricos, experienciais e técnicos, dentro de um processo que não é apenas cognitivo, mas também social e no qual a linguagem assume um essencial papel.

Portanto, a imagem dessa representação social se materializa em desafio, para esses professores especificamente, no contexto cultural e histórico em que estão inseridos, pois na mesma medida em que os professores não possuem formação específica para ser professor na EPS e, mesmo assim, assumem para si o compromisso social da formação profissional em saúde, com a qualificação de profissionais responsáveis pelo cuidado à saúde da atenção básica à alta complexidade, eles se predispõem a encontrar estratégias e usar todos os recursos (formação continuada, parceria institucional, aprendizagem com os pares e educandos, entre outros) para superar as dificuldades encontradas no caminho e organizam suas condutas e comportamentos em torno desse propósito de superação e continuidade de ações no campo da EPS.

Frente ao exposto, acreditamos que a constituição da representação social do ser professor na EPS em desafio reflete a complexidade da rede de sentidos construída pelos participantes e, tendo como base as descrições e análises que antecederam essa conclusão, acreditamos que a formação inicial que tiveram na graduação em saúde é o amálgama que os conduziram à docência, assim como é o ponto de partida da inquietude pelo despreparo didático-pedagógico. O por quê e o para quê são docentes se relacionam com o compromisso social de sua ação educativa e com o valor que atribuem à educação para o trabalho. Por sua vez, o compromisso pessoal e do grupo assumido com esta formação, mesmo diante das dificuldades já discutidas, revela que ao trabalharem em parceria com a gestão e a instituição como um todo, os professores assumem seu papel na garantia de acesso pelos educandos às conquistas científicas e tecnológicas da sociedade.

\section{CONSIDERAÇÕES FINAIS}

Face ao exposto, nos remetemos à importância das representações sociais, através das funções que elas desempenham na compreensão e explicação da realidade desses professores para si e para o grupo (função de saber), na definição da identidade e na proteção do que torna esse grupo, um grupo específico no contexto histórico, social e cultural da EPS na Rede Federal de Ensino (função identitária), na organização de seus comportamentos e práticas (função de orientação) e na justificativa para a tomada de posição e dos comportamentos por eles assumidos (função justificadora). 
O ser professor responsável pela formação em saúde e a construção identitária desses docentes se revelam como aspectos multifacetados, que são construídos no entremear dos saberes cognitivo, técnico, experiencial, entre outros, e da experiência de vida pessoal e profissional dos sujeitos como indivíduos e como integrantes de um coletivo, de um grupo social; no caráter político e social dessa formação e nos aspectos culturais que a caracterizam. Desse modo, constatamos uma dinâmica de construção coletiva do ensino que é fundamental para a formação das representações sociais sobre ser docente para esse grupo de professores.

A representação social do ser professor para estes professores objetivada como imagem em desafio encontra-se fortemente atravessada por pelo menos 06 (seis) questões explicitadas ao longo do estudo e se apresenta pautada nos fatores constituintes do processo ensino-aprendizagem, diretamente e indiretamente relacionados ao professor, assim como integrada aos saberes basilares de sua ação cotidiana.

As questões afetivas estão relacionadas ao planejamento de vida, à identificação com a docência e com a formação em saúde. As questões téoricas envolvem o objetivo formativo da EPS, a regulamentação do ensino profissional e o papel do professor e do estudante. As questões técnicas incluem o domínio dos conhecimentos específicos e didático-pedagógicos e a capacidade de associar na formação do educando teoria e prática.

Por sua vez, as questões psicossociais compreendem o lidar com o outro, as tensões inerentes ao medo, à ansiedade, à inquietação do aprender e do ensinar o cuidado em saúde e a formação integral. As questões históricas emergem das origens da Educação Profissional no Brasil, da superação da fragmentação do ensino e da dissociação teoria-prática-formação humana e cidadã. Finalmente, as questões culturais abarcam o papel da Educação Profissional para a sociedade, a função do professor e do aluno, bem como a forma com a qual se relacionam, o significado do mundo do trabalho, da educação e da saúde para a sociedade em que a escola e seus profissionais estão inseridos.

Nesse sentido, observamos que a forma como os professores se reportam ao objeto ser professor, concebendo-o como desafio nessa formação, advém da pertença social dos indivíduos ao grupo e contexto do qual fazem parte, assim como das implicações de diferentes ordens que norteiam suas condutas e pensamentos.

Pode-se inferir um guia para a ação destes professores nomeadamente relacionada com o compromisso social destes participantes, despertado pela relevância da Educação Profissional em Saúde para o mundo do trabalho e para o tripé educação-trabalho-saúde (elemento da representação social), havendo uma implicação direta entre as atitudes, crenças, opiniões e comportamentos destes professores, sua prática pedagógica, discursos e representações sociais referentes ao ser professor na EPS e os conteúdos teóricos e práticos por eles experienciados e adquiridos durante o processo formativo, o estar e tornar-se professor e a mediação intrínseca ao processo de ensino-aprendizagem.

Nesta abordagem qualitativa sobre as representações do ser professor na Educação Profissional em Saúde, não buscamos generalizar os dados para toda a categoria profissional docente do EBTT na área de saúde, mas objetivamos dar voz e amplitude à discussão sobre essa temática indispensável para a formação de 
trabalhadores de saúde qualificados e capacitados para se inserir no mundo do trabalho.

\section{REFERÊNCIAS}

ARRUDA, Ângela. Despertando do pesadelo: a interpretação. In: PRADO, Clarilza de Sousa et al. Angela Arruda e as representações sociais: estudos selecionados. Curitiba: Champagnat; São Paulo: Fundação Carlos Chagas, 2014. p.116-145.

BRASIL. Ministério da Educação. Lei no 13.005, de 25 de junho de 2014. Aprova o Plano Nacional de Educação - PNE e dá outras providências. Brasília: Congresso Nacional, [2014]. Disponível em: http://www.planalto.gov.br/ccivil_03/_ato20112014/2014/lei//13005.htm. Acesso em: 01 nov. 2017.

BRASIL. Ministério da Educação. Lei no 9.394, de 20 de dezembro de 1996. Estabelece as diretrizes e bases da educação nacional. Brasília: Congresso Nacional, [1996]. Disponível em: http://www.planalto.gov.br/ccivil _03/leis/l9394.htm. Acesso em: 01 nov. 2017.

BRASIL. Ministério da Educação. Lei no 11.741, de 16 de julho de 2008. Altera dispositivos da Lei no 9.394, de 20 de dezembro de 1996, que estabelece as diretrizes e bases da educação nacional, para redimensionar, institucionalizar e integrar as ações da educação profissional técnica de nível médio, da educação de jovens e adultos e da educação profissional e tecnológica. Brasília: Congresso Nacional, [2008]. Disponível em: http://www.planalto.gov.br/ccivil_03/_ato20072010/2008/lei/l11741.htm. Acesso em: 01 nov. 2017.

BRASIL. Ministério da Educação. Decreto n. 5.154 de 23 de julho de 2004. Regulamenta o $\S 2^{\circ}$ do art. 36 e os arts. 39 a 41 da Lei $n^{\circ} 9.394$, de 20 de dezembro de 1996, que estabelece as diretrizes e bases da educação nacional, e dá outras providências. Brasília: Ministério da Educação, 2004. Disponível em: http://www.planalto.gov.br/ccivil_03/_ato2004-2006/2004/decreto/d5154.htm. Acesso em: 01 nov. 2017.

BRASIL. Ministério da Educação. Conselho Nacional de Educação. Parecer n. 11, de 9 de maio de 2012. Dispõe sobre diretrizes curriculares nacionais para a educação profissional técnica de nível médio. Brasília: Ministério da Educação, 2012. Disponível em:

http://portal.mec.gov.br/index.php?option=com_docman\&view=download\&alias $=108$ 04-pceb011-12-pdf\&category_slug=maio-2012-pdf\&ltemid=30192. Acesso em: 01 nov. 2017.

BRASIL. Ministério da Saúde. Conselho Nacional de Saúde. Resolução CNS № 466, de 12 de dezembro de 2012. Aprova as diretrizes e normas regulamentadoras de pesquisas envolvendo seres humanos e revoga as Resoluções CNS nos. 196/96, 303/2000 e 404/2008. Brasília: Conselho Nacional de Saúde, 2012. Disponível em: https://bvsms.saude.gov.br/bvs/saudelegis/cns/2013/res0466_12_12_2012.html>. Acesso em: 01 nov. 2017.

BRASIL. Ministério da Educação. Lei 12.772, de 28 de dezembro de 2012. Dispõe sobre a estruturação do Plano de Carreiras e Cargos de Magistério Federal; sobre a 
Carreira do Magistério Superior, de que trata a Lei oㅜ 7.596, de 10 de abril de 1987; sobre o Plano de Carreira e Cargos de Magistério do Ensino Básico, Técnico e Tecnológico e sobre o Plano de Carreiras de Magistério do Ensino Básico Federal, de que trata a Lei no 11.784, de 22 de setembro de 2008; sobre a contratação de professores substitutos, visitantes e estrangeiros, de que trata a Lei no 8.745 de 9 de dezembro de 1993; sobre a remuneração das Carreiras e Planos Especiais do Instituto Nacional de Estudos e Pesquisas Educacionais Anísio Teixeira e do Fundo Nacional de Desenvolvimento da Educação, de que trata a Lei oㅜ 11.357, de 19 de outubro de 2006; altera remuneração do Plano de Cargos Técnico-Administrativos em Educação; altera as Leis nos 8.745, de 9 de dezembro de 1993, 11.784, de 22 de setembro de 2008, 11.091, de 12 de janeiro de 2005, 11.892, de 29 de dezembro de 2008, 11.357, de 19 de outubro de 2006, 11.344, de 8 de setembro de 2006, 12.702, de 7 de agosto de 2012, e 8.168, de 16 de janeiro de 1991; revoga o art. 4ํ da Lei no 12.677 , de 25 de junho de 2012; e dá outras providências. Brasília: Congresso Nacional, [2012]. Disponível em: http://www.planalto.gov.br/ccivil_03/_ato20112014/2012/lei/l12772.htm. Acesso em: 12 jan. 2021.

JOVCHELOVITCH, Sandra. Representações sociais e polifasia cognitiva: notas sobre a pluralidade e sabedoria da razão. In: ALMEIDA, Angela Maria de Oliveira; SANTOS, Maria de Fatima de Souza; TRINDADE, Zeidi Araújo (org.). Teoria das representações sociais - 50 anos. 2. ed. Brasília: Technopolitik, 2014. p.212-237.

$\mathrm{MOSCOVICI}$, Serge. Representação social: um conceito perdido. In: MOSCOVICI, Serge. A psicanálise, sua imagem e seu público. Petrópolis, RJ: Vozes, 2012. p.39-75. (Coleção Psicologia Social). Tradução de: Sonia Fuhrmann.

VALA, Jorge. Representações sociais: para uma psicologia social do pensamento social. In: VALA, Jorge; MONTEIRO, Maria Benedicta (org.). Psicologia social. 1 ed. Lisboa: Fundação Calouste Gulbenkian, p.353-384, 1993.

VALA, Jorge. As representações sociais no quadro dos paradigmas e metáforas da psicologia social. Análise Social, Lisboa, v. 28, n. 123-124, p. 887-919, 1993.

SÁ, Celso Pereira de. Estudos de psicologia social: história, comportamento, representações e memória. 1. ed. Rio de Janeiro: Eduerj, 2015. 458 p.

JODELET, Denise. Representações Sociais: um domínio em expansão. In: JODELET, Denise.(orgs.). As representações sociais. Rio de Janeiro: Eduerj, 2001. p.17-44. 